\title{
$\bullet$ \\ IJCRR \\ Section: Healthcare \\ Study the Effectiveness of Bilateral Arm Training on Upper Extremity Motor Function and Activity Level in Patients with Sub-Acute Stroke
}

Sci. Journal Impact

Factor: 6.1 (2018)

ICV: 90.90 (2018)

cc) (i) (8)

Copyright@IJCRR

\section{Darshana Dhakate ${ }^{1}$, Radha Bhattad ${ }^{2}$}

\author{
'Assistant Professor, Department of Neuro Sciences, Tilak Maharashtra Vidyapeeth, Pune, India; 'Professor, Department of Neuro- \\ Sciences, Sancheti College of Physiotherapy, Pune, India.
}

\section{ABSTRACT}

Aims and Objectives: To study the effectiveness of Bilateral Arm Training on upper extremity motor function and activity level in patients with sub-acute stroke.

Sample Size: 40 patients (20 in each group), Study Design: Experimental Study, Study setting: Hospitals and Rehabilitation centres in and around the metropolitan city Sample and Sampling method: 40 patients were randomly selected and assigned in 2 groups, as Group 1(conventional group), Group 2 (experimental group) in equal numbers Exclusion Criteria. The total subjects of 40 were included in the study the inclusion and exclusion criteria were Inclusion Criteria: 45 years to 65 years, Both ischemic and hemorrhagic stroke (middle cerebral artery involvement), 1 month from onset to 6 months (sub-acute stage), the score of 21 or higher on mini-mental state examination, Voluntary control grading (Brunnstrom) for upper extremity- Stage 4 Or 5, Patients with a fair grade of sitting balance.

Exclusion Criteria: Upper extremity musculoskeletal disorders e.g. subluxation of shoulder, shoulder pain, any contractures or deformity of any of the upper extremity, Neurological disorders other than stroke, visual impairments, Patients with Unilateral neglect, Patients with perceptual disorders, psychological problems.

Result: There was a significant difference $(p<0.05)$ between mean difference of group $A 82.3 \pm 7.61$ and $89.9+8.23$ and mean difference of group B $83.4 \pm 6.83$ and $87.95 \pm 6.61$ pre and post-treatment scores of Functional Independence Measure (FIM) used to assessed Activity level in subacute stroke similarly Motor Function assessed using Fugl -Meyer assessment UE in patients with subacute stroke in group A pre and post score was $39.3 \pm 3.59$ and $46.15 \pm 3.61$ and for group B it was $38.5 \pm 2.94$ and 42.8 \pm 2.91 respectively.

Conclusion: Bilateral Arm Training proved to be more effective than Conventional Training program to improve affected upper extremity motor function assessed using Fugl- Meyer assessment UE and activity level assessed using Functional Independence Measure and Motor Activity Log in patients with subacute stroke.

Key Words: Bilateral Arm Training, Mins: Minutes, FMA (UE): Fugl- Meyer Assessment (Upper Extremity), MAL: Motor Activity Log, FIM: Functional Independence Measure Scale

\section{INTRODUCTION}

Stroke or brain attack is the sudden loss of neurological function caused by an interruption of the blood flow to the brain, this can be due to ischemia (absence of blood gracefully), brought about by apoplexy or embolism or because of leakage that happens when veins rupture causing spillage of blood in or around brain ${ }^{1}$ Intense stage is considered from the hour of beginning till one month 1 month from onset to 6 months is considered as sub-acute stage whereas more than 6 months is considered as a chronic stage of stroke. ${ }^{1,2}$
Approximately $80 \%$ of all stroke cases are ischemic and most ischemic stroke affects one of the cerebral hemispheres by occlusion of the middle cerebral artery. ${ }^{1}$ The estimated adjusted prevalence rate of stroke range, $84-262 / 100,000$ in rural and 334-424/100,000 in urban areas. The incidence rate is $119-145 / 100,000$ based on recent population-based studies. There is also a wide variation in case-fatality rates with the highest being $42 \%$ in Kolkata. ${ }^{3}$ The term hemiplegia is often used generically to refer to the wide variety of motor problems that result from stroke ${ }^{1 .}$

\section{Corresponding Author:}

Dr. Radha Bhattad, Guide and Professor, Department of Neuro-Sciences, Sancheti College of Physiotherapy, Pune, India. Mobile: 860542511

ISSN: 2231-2196 (Print)

Received: 21.06 .2020
ISSN: $0975-5241$ (Online)

Revised: 17.08 .2020
Accepted: 23.09 .2020
Published: 27.10 .2020 
$20 \%$ to $80 \%$ of the patients show incomplete arm recovery after stroke depending on the initial impairment. Upper limb dysfunction in stroke is characterized by paresis, loss of manual dexterity, and movement abnormalities that may impact considerably on the performance of ADL's ${ }^{5,6}$ The main aim of organized stroke rehabilitation is to achieve a level of functional independence that enables patients to return home and reintegrate into community life that lives up to their expectations and desires as much as possible. ${ }^{18}$

\section{Need for study}

Based on Various strategies, the combination of whole arm functional task training and device-driven bilateral training types. The usage of techniques that involve more functional activities can have a better outcome compared to the other strategies Also it can be seen that the duration of the stroke is a very important variable which can have its effect in the outcome of bilateral arm training treatment sections. Studies in which bilateral arm training have been given to acute patients with post-stroke is comparatively very less in nature concerning sub-acute and chronic patients with post-stroke. Taking this aspect into consideration we have formulated the study frame in an acute case of patients with post-stroke. Thus the need for the study is justified by taking acute patients and conducting an experimental study using bilateral arm training. Hence we are trying to find out the effect of bilateral arm training in improving the upper extremity function among the individuals with acute stroke.

\section{AIMS AND OBJECTIVES}

1) To find out the effect of Bilateral Arm Training on upper extremity motor function assessed using Fugl - Meyer assessment UE scale and activity level assessed using Functional Independence Measure and Motor Activity Log on activity level in patients with sub-acute stroke.

2) To find out the effect of Conventional physiotherapy training on upper extremity motor function assessed using Fugl - Meyer assessment UE scale and activity level assessed using Functional Independence Measure and Motor activity log in patients with sub-acute stroke.

3) To compare the effect of Bilateral Arm Training and Conventional Training on upper extremity motor function assessed using Fugl- Meyer assessment UE and activity level assessed using Functional Independence Measure and Motor activity log in patients with subacute stroke.

\section{MATERIAL AND METHODOLOGY}

\section{Research Design of the Study: Experimental \\ Study}

Study Setting: Hospitals and Rehabilitation centres in and around the metropolitan city

Sample Size: 40 subjects

Sampling Technique: Simple random sampling

Study Duration: 1 year

\section{METHODOLOGY}

The study was conducted after taking approval from the institutional research ethics committee, approval no. P.E.S/ MCOP/387C-2015-2016) in the Department of Neuroscience clearance was obtained from the Institutional ethical committee. Subjects who satisfied the study criteria were enrolled and briefed about the study. Later, Informed Consent was obtained from the subjects in the study. Total of $40 \mathrm{sub}-$ jects was included in the study following the fulfilment of the criteria. 20 subjects in the experimental group (Group A) and 20 patients in the conventional treatment group (Group B) were enrolled.

- All the patients in the experimental group received Bilateral Arm Training (BAT) using 8 Bilateral symmetrical functional activities.

The intervention period was for 4 weeks. ( 5 days a week for 55 minutes which started with 5 min of warm-up exercises followed by bilateral symmetrical functional activities with 10 min rest period after completing 4 activities ${ }^{38}$ Each task performed by the patient for 5 mins.

\section{PROCEDURE}

The Bilateral Arm Training included the following 8 activities-

1) Lift a shoebox overhead and keep it again in front on the table (medium size shoebox)-

Position of the patient: Sitting on a chair comfortably in front of the table

Position of the therapist: Standing by the affected side of the patient

Position of the material: An empty shoebox placed in front of the patient on the table.

Task: Therapist asked the patient to lift a box overhead (holding the width of the box) simultaneously with bilateral upper extremity and keep it again on the table. The same activity was repeated for 5 mins. 


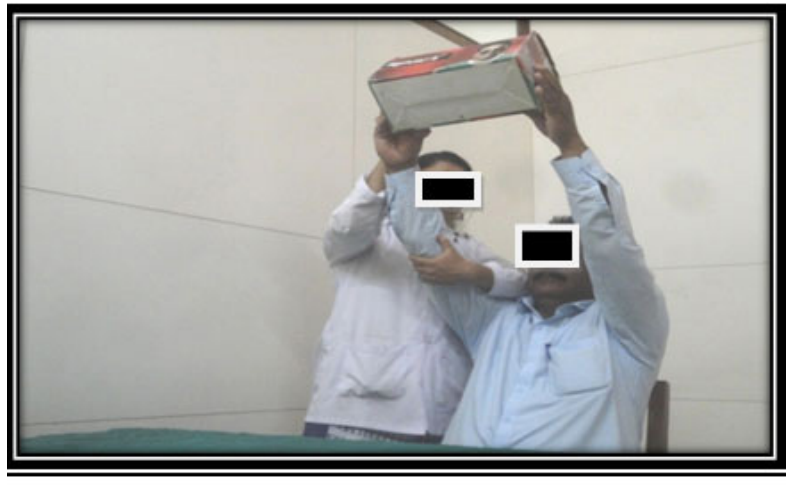

Performing task

Figure 1: The Bilateral Arm Training.

\section{Pull a chair (plastic chair)}

Position of the patient: Sitting on a chair comfortably

Position of the therapist: Standing by the affected side of the patient

Position of the material: A plastic chair with its back facing to the patient kept in front of the patient at his arm's length.

Task: Therapist asked the patient to pull a chair (holding backrest of the chair) simultaneously with bilateral upper extremity towards him while trunk remained still and therapist kept the chair back and again patient asked to pull the chair. The same activity was repeated for 5 mins.

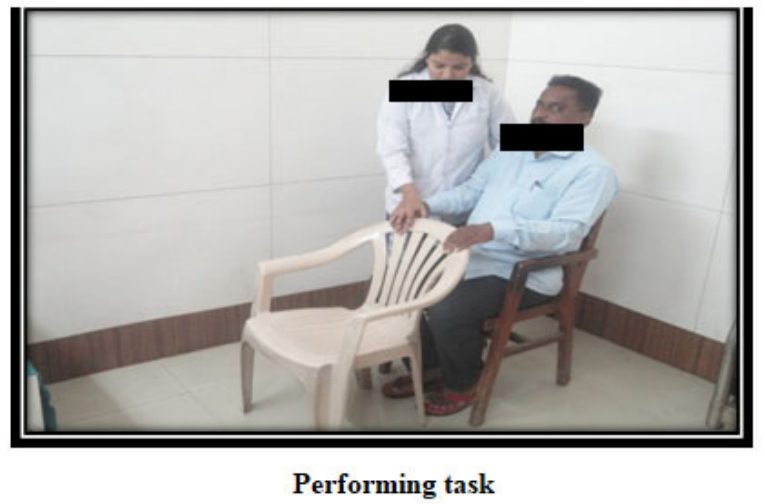

Figure 2: The Bilateral Arm Training.

\section{Lift 2 polystyrene cups simultaneously with} bilateral upper extremity (diameter $8.0 \mathrm{~cm}$, height $10.0 \mathrm{~cm})^{24}$

Position of the patient: Sitting on a chair comfortably in front of the table

Position of the therapist: Standing by the affected side of the patient

Position of the material: 2 polystyrene cups (half waterfilled cups) placed on the table
Task: Therapist asked the patient to lift polystyrene cups (holding one cup by one hand) simultaneously with bilateral upper extremity; then asked the patient to keep it back. The same activity was repeated for 5 mins.

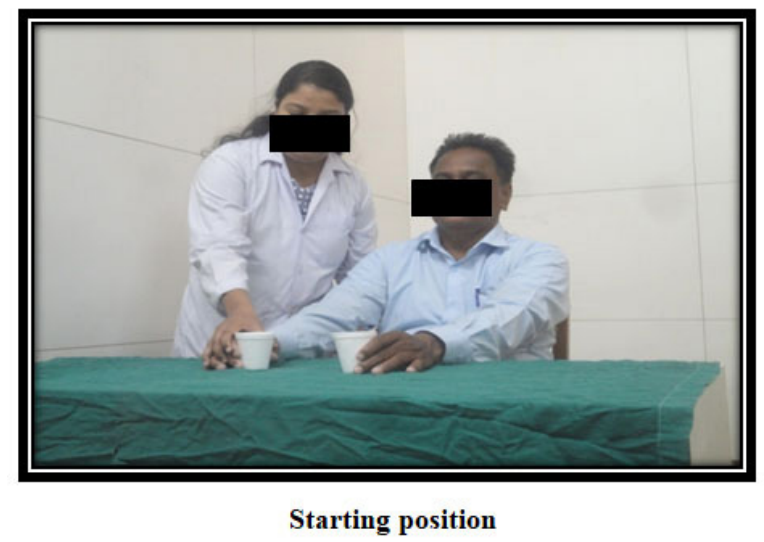

Figure 3: The Bilateral Arm Training.

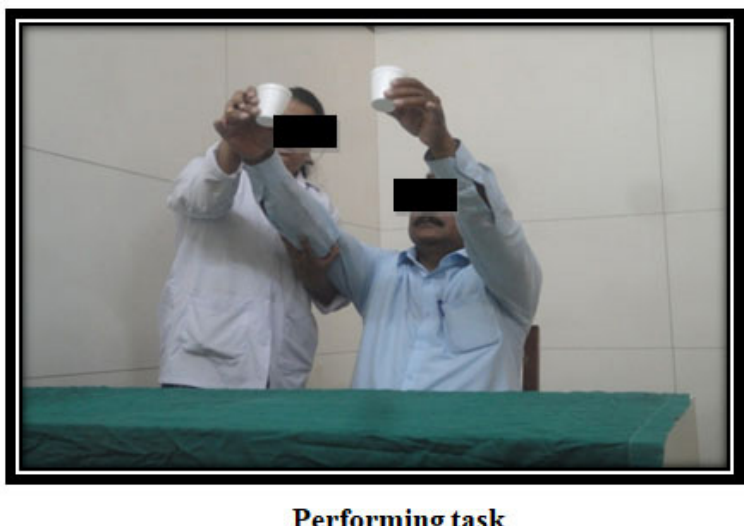

Figure 4: The Bilateral Arm Training.

\section{Conventional Training program:}

All the patients in Group B were treated by using Conventional Physiotherapy Program for affected upper extremity ${ }^{38}$, the affected lower extremity and Trunk . ${ }^{1,19}$

Pre-intervention ( $\mathrm{t} 1$ ) the motor function assessed by using Fugl- Meyer assessment (FMA-UE) scale and activity level was assessed using, Functional Independence Measure scale (FIMS) which is a structured interview and motor activity log scale (structured interview) for the upper extremity.

The Conventional Physiotherapy Program period was for 4 weeks ( 5 days a week for 55 minutes which was started with 5 min of warm-up exercises).

Post-intervention (t2) the motor function assessed by using Fugl- Meyer assessment (FMA-UE) scale and activity level was assessed $t$ using, Functional Independence Measure scale (FIMS) which is a structured interview and 
motor activity log scale (structured interview) for the upper extremity.

\section{Conventional Treatment Progiram included:1, 30, 38} Weight-bearing on the affected UE, Weight shifts, Manipulation activities, Dexterity activities (Holding key)

Dexterity activities (Holding Comb), Functional reaching activities, Co-ordination exercises for affected UE, Gripping activities for affected upper extremity, Each exercise was performed for 5 minutes for affected upper extremity

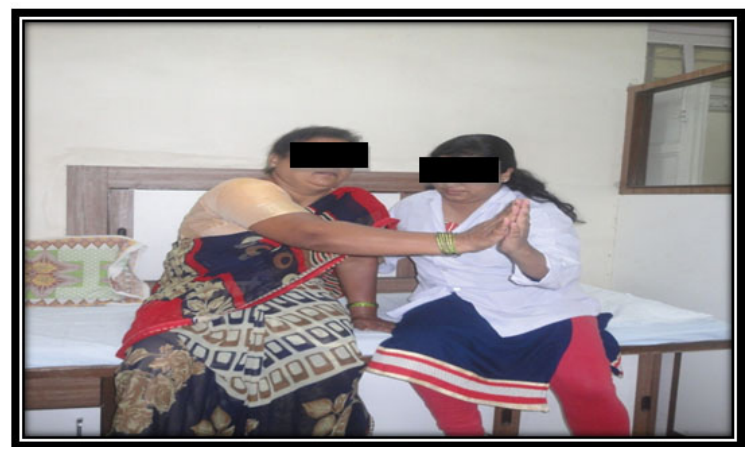

Figure 5: Conventional Training program.

\section{WEIGHT BEARING EXERCISE ON AFFECTED UPPER LIMB}

\section{DATA ANALYSIS}

The Motor function was analyzed using the Fugl- Meyer Assessment Scale for Upper Extremity and Activity level using functional Independence Measure and Motor Activity Log. For this purpose, data were collected by the primary investigator. The data were entered into an excel spreadsheet, tabulated and subjected to statistical analysis.

1) Paired t-test- To see the difference between pre and post measurements within the group.

2) Unpaired t-test- To see the difference between pre and post measurements between the group.

Effect of Bilateral Arm Training and conventional Treatment on Activity level in subacute stroke was analyzed using Nonparametric tests.

1) Wilcoxon sign rank test- to see the difference in the group.

2) Mann Whitney test - To compare between two independent groups. 39

\section{RESULTS}

The Data was analyzed with the help of the Statistical Package of Social Services SPSS (Version 20.0).

There was a significant difference $(\mathrm{p}<0.05)$ between mean difference of group A 82.3+7.61 and 89.9+_8.23 and mean difference of group B 83.4+_6.83 and $87.95+6.61$ pre and post-treatment scores of Functional Independence Measure (FIM) used to the assessed Activity level in subacute stroke similarly Motor Function assessed using Fugl -Meyer assessment UE in patients with subacute stroke in group A pre and post score was $39.3 \pm 3.59$ and $46.15 \pm 3.61$ and for group B it was $38.5 \pm 2.94$ and $42.8 \pm 2.91$ respectively.

Table 1: Distribution of subjects according to the side affected in both the Bilateral Arm Training (Group A) and Conventional Treatment group (Group B) according to the side of affection.

\begin{tabular}{lccc}
\hline Side of affection & $\begin{array}{c}\text { Left Side } \\
\text { Affected }\end{array}$ & $\begin{array}{c}\text { Right Side } \\
\text { Affected }\end{array}$ & Total \\
$\begin{array}{l}\text { GROUP A } \\
\text { (no of subjects) }\end{array}$ & 11 & 09 & 20 \\
$\begin{array}{l}\text { GROUP B } \\
\text { (no of subjects) }\end{array}$ & 12 & 08 & 20 \\
TOTAL & & & 40 \\
\hline
\end{tabular}

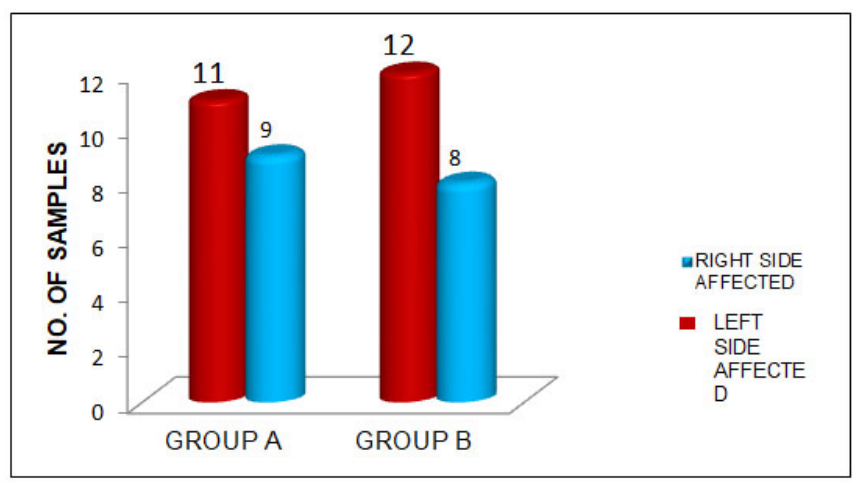

Figure 6: Distribution of subjects according to the side affected in both the Bilateral Arm Training (Group A) and Conventional Treatment group (Group B) according to the side of affection.

Table 2: Showing comparison of pretreatment scores between both groups (Group A, Group B)

\begin{tabular}{|c|c|c|c|c|}
\hline & $\begin{array}{l}\text { GROUP A } \\
\text { Mean } \pm \text { SD }\end{array}$ & $\begin{array}{l}\text { GROUP B } \\
\text { Mean } \pm \text { SD }\end{array}$ & $\begin{array}{c}\text { p-value } \\
(<0.05)\end{array}$ & Result \\
\hline $\begin{array}{l}\text { Fugl Meyer } \\
\text { Assessment } \\
\text { scale UE }\end{array}$ & $39 \cdot 3 \pm 3 \cdot 59$ & $38.5 \pm 2.94$ & 0.44 & $\begin{array}{l}\text { Not Sig- } \\
\text { nificant }\end{array}$ \\
\hline $\begin{array}{l}\text { Functional } \\
\text { independ- } \\
\text { ence Meas- } \\
\text { ure }\end{array}$ & $82.3 \pm 7.61$ & $83.4 \pm 6.83$ & o. 76 & $\begin{array}{l}\text { Not Sig- } \\
\text { nificant }\end{array}$ \\
\hline $\begin{array}{l}\text { MAL } \\
\text { Amount of } \\
\text { use (AOU) }\end{array}$ & $1.03 \pm 0.09$ & $1.00 \pm \ldots .00$ & 0.50 & $\begin{array}{l}\text { Not Sig- } \\
\text { nificant }\end{array}$ \\
\hline $\begin{array}{l}\text { MAL Quality } \\
\text { of movement } \\
\text { (QOM) }\end{array}$ & $1.01 \pm 0.11$ & $0.94 \pm 0.14$ & 0. 09 & $\begin{array}{l}\text { Not Sig- } \\
\text { nificant }\end{array}$ \\
\hline
\end{tabular}




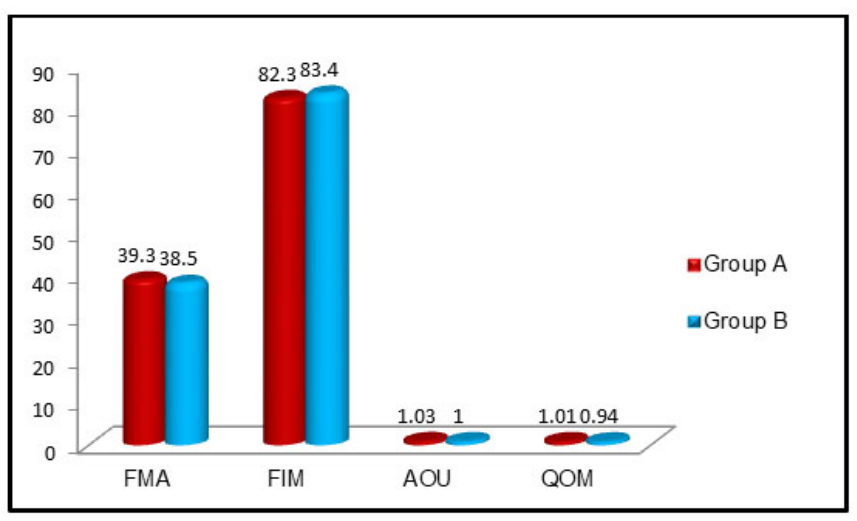

Figure 7: Showing comparison of pre-treatment scores between both groups (Group A, Group B).

Table 3: Comparison of the effect of Bilateral Arm Training (Group A) and Conventional Treatment program (Group B) on Motor Function assessed using Fugl-Meyer assessment UE in patients with subacute stroke.

\begin{tabular}{lcccl}
$\begin{array}{l}\text { FMA UE } \\
\text { PRE } \\
\text { POST }\end{array}$ & $\begin{array}{c}\text { Group } \\
\text { A Mean } \\
\text { difference } \\
\pm \text { SD }\end{array}$ & $\begin{array}{c}\text { Group } \\
\text { B Mean } \\
\text { difference } \\
\pm \text { SD }\end{array}$ & $\begin{array}{c}\text { p- } \\
\text { value } \\
(<0.05)\end{array}$ & Result \\
& $39.3 \pm 3.59$ & $38.5 \pm 2.94$ & 0.44 & Not significant \\
& $46.15 \pm 3.61$ & $42.8 \pm 2.91$ & 0.002 & $\begin{array}{l}\text { Extremely } \\
\text { significant }\end{array}$ \\
\hline
\end{tabular}

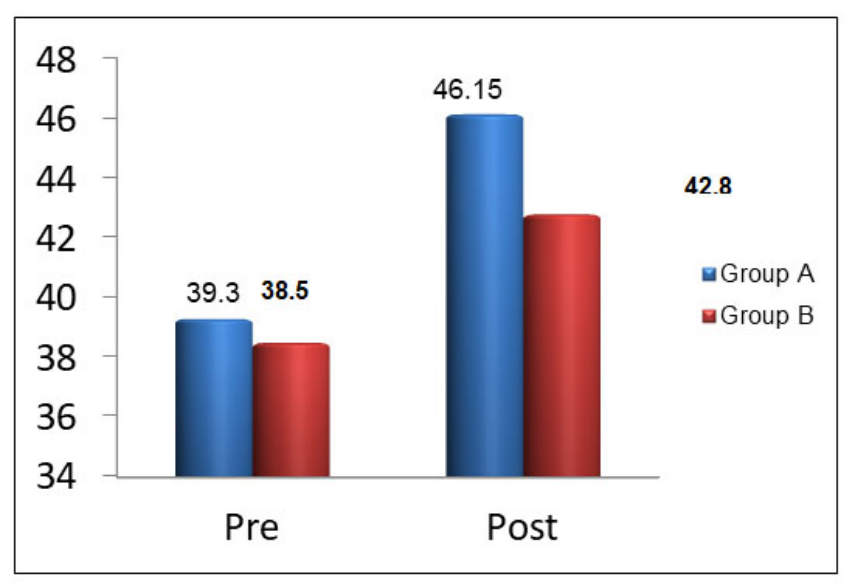

Figure 8: Comaparison between Group A and Group B assesed using FMA.

There was a significant difference $(p<0.05)$ between the mean difference of group A and mean difference of Group B post-treatment scores of Fuglmeyer assessment UE used to assessed motor function in subacute stroke patients.

\section{DISCUSSION}

The present study was undertaken to see the effectiveness of Bilateral Arm Training on upper extremity motor function assessed using Fugl -Meyer assessment UE scale and Activity level assessed using Functional Independence Measure and Motor Activity Log in patients with Sub-acute stroke. In this study total 40 patients, both males and females were included with 20 participants in each group (Bilateral Arm Training and Conventional Treatment Group) with mean age $54 \pm 10$ years.

In this study, we found that Bilateral Arm Training is effective in improving motor function and activity level of the upper extremity in sub-acute stroke patients. So also, traditional treatment is viable in improving motor capacity and an action level of in sub-intense stroke patients, Further on, comparing Bilateral Arm Training with conventional training we found that Bilateral Arm Training is more effective in improving motor function and activity level of the upper extremity in subacute stroke patients.

Our results are in account with EQ van Delden et al; they reported that Bilateral Arm Training with rhythmic auditory cueing (BATRAC), has beneficial effects on the paretic arm in chronic stroke patients, possibly as a result of changes in contralesional cortical networks ${ }^{37}$.

Activity Log but there was no significant improvement in functional performance when assessed using Functional Independence Measure in chronic stroke patients. The possible reason that they did not found a significant difference in improving functional performance assessed using Functional Independence Measure could be their study had small sample size, small intervention period, the population i.e. chronic stroke and very less bilateral symmetrical activities whereas in our study we found that 4 weeks of BAT improves motor function assessed using Fugl- Meyer assessment UE and activity level assessed using Functional Independence Measure and Motor Activity Log. ${ }^{13}$

Also, Summers JJ et al. in chronic stroke patients found that chronic stroke patients receiving Bilateral Training showed a reduction in movement time of the impaired limb and increased upper extremity functional ability compared to individuals receiving unilateral training in chronic stroke patients. Their study results are in account with our study results but we have not considered movement time in our study. ${ }^{10}$

Our study results are consistent with Stinear et al. ${ }^{28}$ who reported that a 4 weeks bilateral training approach (activepassive bilateral therapy) helps to improve the motor control when assessed using Fugl- Meyer assessment scale UE in patients with chronic stroke.

Only sub-acute stroke subjects were enrolled for training in our study as only a few reports are available on the effect of 
training regimens focusing on bilateral use of upper limbs in both acute and sub-acute phases.

Stewart KC, Cauraugh et al. revealed a strong Bilateral Arm movement training effect and improved motor capabilities post-stroke. They reported that unilateral movements may generate an inter-hemispheric inhibition in the ipsilateral hemisphere that prevents mirror movements in the opposite upper limb. In contrast, Bilateral movement activates similar neural distributed networks in both the hemisphere, allowing mirror movements. ${ }^{(15,26)}$

In contrast with our study results, Morris et al. ${ }^{11}$ did not show a significant difference between the benefits of Bilateral Arm Training and unilateral arm training when compared in chronic stroke patients; perhaps because these investigations depended on a little preliminary with heterogeneous qualities of study subjects (eg, time after the beginning of stroke).

In contrast with our study results, Syed et al. ${ }^{14}$ found that 3 weeks of Bilateral Arm Training improves functional performance better than Unilateral Arm Training, but they found improvement in the amount of use component but not in the quality of movement component of Motor Activity Log. Whereas in our study we found improvement in both the components of Motor Activity Log. The probable reasoning for difference in the results could be that their study was a small trial, with small sample size, small intervention period ( 3 weeks); they have taken only 3 functional tasks in their study and the population was generalized i.e. both sub-acute and chronic stage were included.

Lewis $\mathrm{GN}^{20}$ et al. who reported that, when a neurologically intact individual performs a unilateral movement, interhemispheric inhibition (Transcollosal inhibition) of the non-target hand occurs to enhance independent bimanual control of each limb. Whereas, during the bilateral movement, independent control of each limb is not essential, rendering transcallosal inhibition unnecessary. Our findings concur to those of Cunningham et al. ${ }^{40}$ who reported inter-limb coupling dynamics with bilateral extremity training in turn leading to a better amount of use (AOU) and quality of movement (QOM) of affected extremity in chronic stroke patients.

Useful recuperation of the furthest point is advanced by plastic changes in the working of the cerebrum, which, when all is said in done, likewise happen in learning ${ }^{42}$. These experience initiated changes are achieved by a blend of neural fix and neuron-anatomic revamping and incorporate more prominent volatility and enrollment of the neurons in both hemispheres, sprouting of dendrites, and strengthening of synaptic connections ${ }^{42,46,48}$

This proposes motor work in the weakened paretic arm might be recovered by exploiting inter-hemispheric interactions. In particular, based on the principle of inter-hemispheric recruitment from the non-affected hemisphere (i.e., exercise- induced neuroplasticity employing "neural crosstalk"), Bilateral Arm Training may serve as an effective therapy for patients in whom the corticospinal tract (CST) system is seriously affected. (29)

A variety of functional symmetric tasks were incorporated into the BAT program in our study that allowed repetitive practice on skilled movements. Repetitive exercises/ practice help to activate weak paralyzed muscles as well as Taskrelated training to improve strength and coordination ${ }^{50}$. As well as the practice of meaningful tasks/ functional tasks and specific exercises also allows the damaged system to regain the ability to select and use those sensory inputs which are relevant to the action being practised.

Thus, the overall findings of this study suggest that 4 weeks of Bilateral Arm Training is a better approach than conventional rehabilitation to improve upper extremity motor function and activity level in patients with sub-acute stroke.

\section{CONCLUSIONS}

In this study both the groups i.e. Group A (Bilateral Arm Training) and group B (Conventional Treatment program) showed improvement of affected upper extremity Motor function and activity level in patients with subacute stroke.

But on comparing both the training groups statistically, Bilateral Arm Training proved to be more effective than Conventional Training program to improve affected upper extremity motor function assessed using Fugl- Meyer assessment UE and activity level assessed using Functional Independence Measure and Motor Activity Log in patients with subacute stroke.

Hence alternative hypothesis (H1) is accepted; Bilateral Arm Training will show significant effect than conventional treatment to improve upper extremity motor function and activity level in patients with sub-acute stroke.

\section{ACKNOWLEDGEMENT}

Authors acknowledge the immense help received from the scholars whose articles are cited and included in references to this manuscript. The authors are also grateful to authors/ editors/publishers of all those articles, journals and books from where the literature for this article has been reviewed and discussed.

\section{Conflict of interest}

Authors declare there is no conflict of interest.

\section{Funding}

Self Financed 


\section{REFERENCES}

1. Sullivan OS. Physical rehabilitation: 5th ed. 2007: 705-775.

2. Murase N, Duque J, Mazzocchio R, Cohen LG. Influence of interhemispheric interactions on motor function in chronic stroke. Ann Neurol 2004;55:400-409. [PubMed: 14991818]

3. Jeyaraj Durai, Pandian, A Paulin Sudhanb. Stroke Epidemiology and Stroke Care Services in India Journal of Stroke:2013;15(3):128-134

4. Platz $\mathrm{T}$, winter $\mathrm{T}$ et al. Arm ability training for stroke and traumatic brain injury patients with mild arm paresis: a single-blind randomized controlled trial. Arch Phys Med Rehab:2001;82;961-96.

5. Nakayama H, Jorgensen HS, RaaschouHparkerO, Olsen TS. Recovery of Upper Extremity Function in Stroke Patients: The Copenhagen Study. Archives of Physical Medicine and Rehabilitation 1994;75:852-857. [PubMed: 8053790]

6. Anne Shumway-cook, Marjorie H. Woollacott. Motor control translating research into clinical practice; 3rd edition.

7. Mudie MH, Matyas TA. Can simultaneous bilateral movement involve the undamaged hemisphere in the reconstruction of neural networks damaged by stroke? Disabil Rehabil 2000; 22: 23-37.

8. Luft A, McCombe Waller S, et al. Repetitive bilateral arm training and motor cortex activation in chronic stroke. A randomized controlled trial.JAMA. 2004;292:1853-1861.

9. Hesse S, Werner C, Pohl M, Rueckriem S, Mehrholz J, Lingnau ML. Computerized arm training improves the motor control of the severely affected arm after stroke. A single-blinded randomized trial in two centres. Stroke. 2005;36:1960-1966.

10. Summers JJ, Kagerer FA, Garry MI, Hiraga CY, Loftus A, Cauraugh $\mathrm{JH}$. Bilateral and unilateral movement training on upper limb function in chronic stroke patients: a TMS study. J Neurol Sci. 2007;252:76-82.

11. Morris JH, van Wijck F, Joice S, Ogston SA, Cole I, MacWalter RS. A comparison of bilateral and unilateral upper-limb task training in early poststroke rehabilitation: a randomized controlled trial. Arch Phys Med Rehabil. 2008;89:1237-1245.

12. Mudie MH, Matyas TA. Upper extremity retraining following stroke: effects of the bilateral practice. J NeurolRehabil. 1996;10:167-184.

13. Chung Lin SD, Yi A, Chen MS et al: The effects of Bilateral arm training on motor control and functional performance in chronic stroke: A randomized controlled trial: Neurorehabilitation and neural repair: 2010

14. Nafeez Syed, AbhisekBiswas, Bilateral Versus Unilateral Upper Extremity Training on Upper Limb MotorActivity in Hemiplegia; Int J Neurorehabilitation 2015, 2:1

15. Cauraugh JH; Two coupled motor recovery protocols are better than one; EMG triggered neuromuscular stimulation and bilateral movement; stroke 2002;33:1589-94

16. Whitall J, McCombe Waller S, Silver KHC, Macko RF. Repetitive bilateral arm training with rhythmic auditory cueing improves motor function in chronic hemiparetic stroke. Stroke. 2000;31:2390-2395.

17. NeuroRehabilitation. Author manuscript. Bilateral arm training why and who benefits? NIH-PA Author Manuscript. 2010.

18. VanPeppen RP, Kwakkel G, Wood-Dauphinee S, Hendriks HJ, WeesPJ Van der, Dekker J: The impact of physical therapy on functional outcomes after stroke: what's the evidence? ClinicalRehabilitation. 2004, 18(8):833-862.
19. Kaplan PE, Cailliet R, Kaplan CP: Rehabilitation of stroke. 1st edition.Burlington: Butterworth-Heinemann; 2003.

20. Lewis GN, Byblow WD. Neurophysiological and behavioural adaptations to a bilateral training intervention in individuals following stroke. Clin Rehabil. 2004;18:48-59.

21. Richards LG, Senesac CR, Davis SB, Woodbury ML, Nadeau SE. Bilateral arm training with rhythmic auditory cueing in chronic stroke: not always efficacious. Neurorehabil Neural Repair. 2008;22:180-184.

22. Schaechter JD. Motor rehabilitation and brain plasticity after hemiparetic stroke. Prog Neurobiol. 2004;73:61-72.

23. Nyeonju Kang, Jerelyne Idica1, Bhullar Amitoj1 and James H Cauraugh2; Motor recovery patterns in arm muscles: coupled bilateral training and neuromuscular stimulation; J. NeuroEngg. Rehabilitation. 2014, 11:57.

24. Duncan PW, Propst M, Nelson SG: Reliability of the Fugl-Meyerassessment of sensorimotor recovery following cerebrovascular accident. Physical therapy 1983, 63(10):1606-1610

25. McCombe Waller S, Whitall J. Bilateral arm training: why and who benefits? Neuro Rehabilitation. 2008;23:29-41.

26. StewartkC, Cauraugh JH, Summers JJ. Bilateral movement training and stroke rehabilitation: a systematic review and metaanalysis. J Neurosci 2006; 244: 89-95

27. Park Y: The effect of mirror therapy with task-specific training on upper extremity function and self-care in stroke patients; J. Phy Ther. 27:1499-1501:2015

28. Stinear JW, Byblow WD. Rhythmic bilateral movement training modulates corticomotor excitability and enhances upper limb motricity post stroke: a pilot study. J Clin Neurophysiol.2004;21:124-131.

29. EQ van Delden, C (Lieke) E Peper,: Comparing unilateral and bilateral upper limb training: TheULTRA-stroke program design.BMC Neurology 2009, 9:57

30. Umphred, Darcy A. Neurological rehabilitation; fifth edition.

31. Feys HM, De Weerdt WJ, Selz BE, Cox Steck GA, Spichiger $R$, et al. Effect of a therapeutic intervention for the hemiplegic upper limb in the acute phase after stroke: a single-blind, randomized, controlled multicenter trial. Stroke. 1998; 29: 785-792.

32. Uswatte G, Giuliani G, Winstein C, Zeringue A, Hobbs L, Wolf SL. The validity of accelerometry for monitoring real-world arm activity in patients with subacute stroke: evidence from the extremity constraint-induced therapy evaluation trial. ArchPhys Med Rehabil. 2006;87:1340-1345

33. Fugl-Meyer AR, Jaasko L, Leyman I, Olsson S, Steglind S: The post-stroke hemiplegic patient. A method for evaluation of physical performance.Scand J Rehabil Med 1975, 7:13-31

34. McCombe Waller S, Liu W, Whitall J. Temporal and spatial control following bilateral versus unilateral training. Hum Mov Sci. 2008;27:749-758.

35. Keith RA, Granger CV, Hamilton BB, Sherwin FS: The functional independence measure: a new tool for rehabilitation. Adv Clin Rehabil1987, 1:6-18.

36. Edward Taub, Karen McCulloch: UAB CI Therapy Research Group: Motor activity log:2011

37. McDonnell MN, Hillier SL (2007) Influence of combined afferent stimulation and task-specific training following stroke: a pilot randomized controlled trial. Neurorehabil. Neural Repair. 21:435-443. 